\title{
IL-27-producing CD14(+) cells infiltrate inflamed joints of rheumatoid arthritis and regulate inflammation and chemotactic migration.
}

\section{$\operatorname{AUTHOR}(\mathrm{S})$ :}

Tanida, Shimei; Yoshitomi, Hiroyuki; Ishikawa, Masahiro; Kasahara, Takashi; Murata, Koichi; Shibuya, Hideyuki; Ito, Hiromu; Nakamura, Takashi

\section{CITATION:}

Tanida, Shimei ...[et al]. IL-27-producing CD14(+) cells infiltrate inflamed joints of rheumatoid arthritis and regulate inflammation and chemotactic migration.. Cytokine $2011,55(2): 237-244$

\section{ISSUE DATE:}

2011-08

URL:

http://hdl.handle.net/2433/162019

\section{RIGHT:}

(C) 2011 Elsevier Ltd.; This is not the published version. Please cite only the published version.; この論文は出版社版でありません。引用の際に は出版社版をご確認ご利用ください。 
IL-27-producing CD14 ${ }^{+}$cells infiltrate inflamed joints of rheumatoid arthritis and regulate inflammation and chemotactic migration.

Shimei Tanida, Hiroyuki Yoshitomi, Masahiro Ishikawa,

Takashi Kasahara, Koichi Murata, Hideyuki Shibuya, Hiromu Ito, Takashi Nakamura

Department of Orthopaedic Surgery, Kyoto University Graduate School of Medicine, Kyoto 606-8507, Japan

Research highlights

The IL-27 level in synovial fluid of RA is significantly higher than that of OA.>IL-27 in RA joints is derived from $\mathrm{CD}^{+} 4^{+}$cells.> $\mathrm{IL}^{2} 7^{+} \mathrm{CD} 14^{+}$cells significantly infiltrate into $\mathrm{RA}$ synovium.>WSX-1 is ubiquitously expressed on RA synovium.>IL-27 suppresses the production of IL-6 or CCL20 from RA fibroblast-like- synoviocytes.

Key Words

Rheumatoid arthritis, IL-27, CCL20, Th17, CD14

Please address all correspondence to:

Hiroyuki Yoshitomi, MD, PhD

Department of Orthopaedic Surgery

Kyoto University Graduate School of Medicine

54 Shogoin Kawahara-cho, Sakyo-ku

Kyoto 606-8507, Japan

Phone +81-75-751-3652

Fax +81-75-751-8409

E-mail yositomi@kuhp.kyoto-u.ac.jp 


\section{Abstract}

Interleukin (IL)-27, a heterodimeric cytokine, has been reported to be involved in the pathogenesis of autoimmune diseases through mediating differentiation of Th1 or Th17 cells and immune cell activity or survival. However, the origin and effects of IL-27 in joints of rheumatoid arthritis (RA) remain unclear. In this study, we investigated the distribution and anti-inflammatory roles of IL-27 in RA synovium. The IL-27 levels in plasma of RA patients, osteoarthritis (OA) patients, or healthy volunteers ( $\mathrm{n}=15$ per group) were equivalent and were at most $1 \mathrm{ng} / \mathrm{ml}$, but the IL-27 level in synovial fluid of RA patients $(\mathrm{n}=15$, mean $0.13 \mathrm{ng} / \mathrm{ml}$; range $0.017-0.37 \mathrm{ng} / \mathrm{ml})$ was significantly higher than that in synovial fluid of OA patients $(\mathrm{n}=15$, mean $0.003 \mathrm{ng} / \mathrm{ml}$; range $0-0.033 \mathrm{ng} / \mathrm{ml}$ ) and potentially lower than in plasma. We analyzed the protein level of IL-27 produced by RA fibroblast-like synoviocytes (FLSs) or mononuclear cells (MNCs) from RA or OA synovial fluid or peripheral blood and showed that IL-27 in RA joints was derived from MNCs but not from FLSs. We also found by flow cytometry that IL-27-producing MNCs were CD14 ${ }^{+}$, and that these $\mathrm{CD} 14^{+} \mathrm{IL}-27^{+}$cells were clearly detected in RA synovium but rarely in OA synovium by immunohistochemistry. Furthermore, we demonstrated that a relatively physiological concentration of IL-27 below $10 \mathrm{ng} / \mathrm{ml}$ suppressed the production of IL-6 and CCL20 from RA FLSs induced by proinflammatory cytokines through the IL-27/IL-27R axis. In the synovial fluid of RA, the IL-27 level interestingly had 
positive correlation with the IFN- $\gamma$ level $(\mathrm{r}=0.56, \mathrm{p}=0.03)$, but weak negative correlation with the IL-17A level $(r=-0.30, p=0.27)$, implying that IL-27 in inflammatory joints of RA induces Th1 differentiation and suppresses the development or the migration of Th17 cells. These findings indicate that circulating IL-27-producing $\mathrm{CD} 14^{+}$cells significantly infiltrate into inflamed regions such as RA synovium and have anti-inflammatory effects in several ways: both directly through the reduction of IL-6 production, and possibly through the induction of Th1 development and the suppression of Th17 development; and indirectly by regulation of recruitment of $\mathrm{CCR}^{+}$cells, such as Th17 cells, through the suppression of CCL20 production. Our results suggest that such a serial negative feedback system could be applied to RA therapy.

\section{Introduction}

Rheumatoid arthritis (RA) is a chronic inflammatory autoimmune disease, manifesting as systemic inflammatory arthritis with hypertrophy of the synovium followed by the destruction of cartilage, bone and joint structures. Several in vivo experimental autoimmune animal models and in vitro human studies have suggested that interleukin (IL)-17-secreting helper T (Th17) cells can be considered a critical mediator of RA with respect to tissue inflammation or bone resorption [1-4]. Th17 cells specifically express chemokine receptor CCR6, and its ligand CCL20 recruits Th17 cells $[1,5]$. An association of the dinucleotide polymorphism of the CCR6 gene (CCR6DNP) with RA susceptibility has been suggested [6]. 
IL-27 is a recently identified cytokine, which is structurally related to IL-12 as a heterodimeric cytokine, similar to IL-23 and IL-35. IL-27 is composed of Epstein-Barr virus-induced gene 3 (EBI3), a p40-related molecule, and IL-27p28, a p35-related molecule [7]. IL-27 is produced by antigen presenting cells (APCs) including dendritic cells (DCs) and monocytes, and is secreted as a heterodimer [8]. IL-27 is reported to be expressed at chronic inflammatory sites, such as synovial tissues in RA [9], skin lesions in psoriasis [10], inflamed intestine in Crohn's disease, and granulomas in tuberculosis or sarcoidosis [11]. IL-27 suppresses the development of Th17 cells and the production of cytokines including IL-17A from activated $\mathrm{CD}^{+} \mathrm{T}$ cells by blocking RAR-related orphan receptor $\mathrm{C}$ (RORC) expression in humans and in several experimental animal models, while it induces Th1 differentiation [9, 12-15].

IL-27 receptor (IL-27R) is also a heterodimer of WSX-1 (IL-27R $\alpha$ ), a homologue of IL-12R $\beta 2$, and gp130, a component of the IL-6 receptor $[16,17]$. Both components are coexpresssed in various human cell types, including monocytes, DCs, T cells, B cells, natural killer cells, mast cells and endothelial cells, and both components are required for the signal transduction of IL-27 [17]. Downstream of IL-27R, mainly STAT1 and STAT3 are activated [17, $18]$.

In a murine collagen-induced arthritis (CIA) model, administration of IL-27 reduces the amount of serum IL-6, cellular infiltration to the joints, synovial hyperplasia and joint erosion at 
the onset of the disease [9]. IL-27 also inhibits human receptor of NF-אB ligand

(RANKL)-mediated osteoclastogenesis $[19,20]$. These reports suggest protective roles for IL-27

in the pathogenesis of arthritis. In contrast, it is also reported that IL-27 possesses pathogenic roles in RA. In experimental animal models of adjuvant-induced arthritis and proteoglycan-induced arthritis, IL-27 is critically involved with the development of arthritis by inducing the differentiation of naïve T cells into interferon (IFN)- $\gamma$-producing Th1 cells [21, 22]. In humans, high concentrations of IL-27 induce the production of IL-6 and inflammatory chemokines from FLSs of established RA [23]. These conflicting reports reflect the complex functions of IL-27 in human immunology.

In this study, we investigated the source and role of IL-27 in RA. We show that IL-27-producing CD14 ${ }^{+}$cells significantly infiltrate RA synovium, and that physiological concentrations of IL-27 could have anti-inflammatory effects in several ways: both directly through the suppression of IL-6 production and possibly through Th1 differentiation; and indirectly by regulating recruitment of $\mathrm{CCR}^{+}$cells including Th17 cells through the suppression of CCL20 production. Our results suggest that IL-27 might be a potential therapeutic agent for RA. 


\section{Material and methods}

\subsection{Cytokines and reagents}

Human recombinant tumor necrosis factor (TNF)- $\alpha$, human recombinant IL-1 $\beta$, human recombinant IL-6, human recombinant soluble IL-6 receptor (sIL-6R), and human recombinant IL-17A were purchased from PeproTech USA (Rocky Hill, NJ, USA). The following reagents were purchased from R\&D Systems (Minneapolis, MN, USA): human recombinant IL-27, anti-human TCCR/WSX-1 antibody, isotype control IgG, human TCCR/WSX-1 Fc chimera, human IgG1 Fc, anti-human IL-27 antibody and isotype control IgG. Anti-human CD8a antibody, anti-human CD4 antibody, anti-human CD19 antibody and anti-human CD14 antibody were purchased from eBioscience (San Diego, CA, USA).

\subsection{Ethics approval}

Ethics approval for this study was granted by the ethics committee of Kyoto University Graduate School and Faculty of Medicine, and written consent was obtained for every sample. Informed consent was obtained from 69 participants (28 with RA, 26 with knee osteoarthritis (OA), and 15 as healthy volunteers (HV)). The clinical features of participants in this study are summarized in Table 1. RA and OA were diagnosed according to the criteria of the American College of Rheumatology. 


\subsection{Preparation of peripheral blood and synovial fluid samples}

Peripheral blood samples were collected in ethylenediaminetetraacetic acid dipotassium salt (EDTA-2K)-containing tubes to separate the plasma. After both peripheral blood and synovial fluid samples were centrifuged at $400 \times g$ for $7 \mathrm{~min}$, the supernatants were stored at -20 ${ }^{\circ} \mathrm{C}$ until analysis.

\subsection{Isolation of mononuclear cells (MNCs)}

After centrifugation of peripheral blood and synovial fluid samples, the pellets were suspended in RPMI-1640 (Sigma-Aldrich, St Louis, MO, USA) with 1\% fetal bovine serum (FBS; ICN, Aurora, OH, USA). Debris was removed from the synovial fluid samples with a 70 $\mu \mathrm{m}$ cell strainer (BD Biosciences, Basel, Switzerland). Each sample was layered on the same amount of Histopaque-1077 (Sigma-Aldrich). After centrifugation at $400 \times g$ for $30 \mathrm{~min}$ at room temperature, MNCs were collected and washed twice with PBS.

\subsection{MNC culture}

Isolated MNCs were suspended in RPMI-1640 with $1 \% \mathrm{FBS}$, and $1 \times 10^{6} \mathrm{MNCs}$ were 
stimulated with $20 \mathrm{ng} / \mathrm{ml}$ phorbol myristate acetate (PMA, Sigma-Aldrich) and $1 \mu \mathrm{M}$ ionomycin (Sigma-Aldrich) in 24-well ultralow cluster plates (Costar, New York, USA). After $4 \mathrm{~h}$ incubation at $37{ }^{\circ} \mathrm{C}$ in a humidified $5 \% \mathrm{CO}_{2}$ atmosphere, the medium with suspended MNCs was collected and centrifuged at $400 \times g$. Supernatants and MNCs were used separately for analysis.

\subsection{Fibroblast-like synoviocyte (FLS) culture}

Human synovial tissues were obtained during total knee replacement surgery in Kyoto University Hospital from RA patients fulfilling the revised criteria of the American College of Rheumatology. FLSs of RA patients were prepared as previously reported [5]. Briefly, the tissues were minced into small pieces and digested with $2 \mathrm{mg} / \mathrm{ml}$ collagenase (Wako, Osaka, Japan) in Dulbecco's modified Eagle's medium (DMEM, Sigma-Aldrich) containing 100 U/ml penicillin and $100 \mu \mathrm{g} / \mathrm{ml}$ streptomycin at $37^{\circ} \mathrm{C}$ for $2 \mathrm{~h}$, followed by digestion with $0.05 \%$ trypsin and $0.02 \%$ ethylenediaminetetraacetic acid (EDTA) at $37^{\circ} \mathrm{C}$ for $30 \mathrm{~min}$. The cells were cultured in DMEM containing $10 \%$ FBS in $100 \mathrm{~mm}$ dishes (Iwaki, Tokyo, Japan) at $37^{\circ} \mathrm{C}$ in a humidified 5\% $\mathrm{CO}_{2}$ atmosphere. After 3-7 passages, FLSs were plated in 12-well plates (Corning, NY, USA) in DMEM containing 10\% FBS. At confluence, FLSs were washed twice with phosphate-buffered saline (PBS) and stimulated with various concentrations of cytokines in serum-free DMEM for $48 \mathrm{~h}$, and the supernatant or the cell layer was then collected for further 
analyses.

\subsection{Measurement of cytokines and chemokines}

The concentration of human TNF- $\alpha$, IL- $1 \beta$, IL-6, IL-17A and IFN- $\gamma$ was measured by ELISA (eBioscience), with detection limits of $1.55 \mathrm{pg} / \mathrm{ml}, 1.37 \mathrm{pg} / \mathrm{ml}, 1.61 \mathrm{pg} / \mathrm{ml}, 3.64 \mathrm{pg} / \mathrm{ml}$ and $1.18 \mathrm{pg} / \mathrm{ml}$ respectively. The concentration of human CCL20 was measured by ELISA (R\&D Systems), with a detection limit of $0.17 \mathrm{pg} / \mathrm{ml}$. The concentration of IL-27 was measured by ELISA (Biolegend, San Diego, CA, USA), with a detection limit of $11 \mathrm{pg} / \mathrm{ml}$.

\section{8 . Immunohistochemical staining}

FLSs that were seeded in Lab-Tek chamber slides (Nalge Nunc International, Rochester, NY, USA) were fixed in $4 \%$ paraformaldehyde. RA synovium was fixed in $4 \%$ paraformaldehyde, embedded in paraffin and then sectioned and dewaxed. The endogenous peroxidase activity in both sample types was blocked with $0.6 \%$ hydrogen peroxide in methanol for $30 \mathrm{~min}$. Anti-WSX-1 antibody $(10 \mu \mathrm{g} / \mathrm{ml})$ was applied, and the sections were incubated for $30 \mathrm{~min}$ at room temperature. The equivalent normal goat $\mathrm{IgG}$ was used as a negative control. The reaction products were visualized using Vectastain ABC Kit and DAB Peroxidase Substrate Kit (both from Vector Laboratories, Burlingame, CA, USA) according to the manufacturer's instructions. The sections were counterstained with hematoxylin for $2 \mathrm{~min}$. 


\subsection{Flow cytometry}

Isolated MNCs were suspended in RPMI-1640 with $10 \% \mathrm{FBS}$, and $1 \times 10^{6}$ MNCs were stimulated with $20 \mathrm{ng} / \mathrm{ml}$ PMA (Sigma-Aldrich), $1 \mu \mathrm{M}$ ionomycin (Sigma-Aldrich) and 0.67 $\mu \mathrm{l} / \mathrm{ml}$ GolgiStop (BD Biosciences) in 24-well ultralow attachment plates (Costar). After $4 \mathrm{~h}$ incubation at $37^{\circ} \mathrm{C}$ in a humidified $5 \% \mathrm{CO}_{2}$ atmosphere, MNCs were stained for CD4, $\mathrm{CD} 8$, CD14, CD19 and intracellular IL-27, and analyzed on a BD FACSCanto II ${ }^{\mathrm{TM}}$ (BD Biosciences).

\subsection{Confocal microscopy}

Detection of CD14 and intracellular IL-27 present in the frozen sections of synovium tissues from RA or OA patients was performed using a laser confocal microscope (AZ-C1; Nikon, Tokyo, Japan). Briefly, a piece of fresh synovium from RA or OA patients was embedded in Tissue-Tek O.C.T. compound (Sakura Finetechnical Co. Ltd., Tokyo, Japan) and frozen in liquid nitrogen. This frozen block, stored at $-80^{\circ} \mathrm{C}$ until usage, was cut $10-40 \mu \mathrm{m}$ thick in the Leica CM1850 cryostat (Leica Microsystems, Wetzler, Germany) and mounted on Superfrost-plus slides. After fixation with $4 \%$ paraformaldehyde and blocking with $10 \%$ normal serum, the frozen sections were stained with directly conjugated antibodies. 


\subsection{Statistical analysis}

Student's $t$-test was used for statistical analyses unless indicated otherwise. $P<0.05$ was considered significant. The correlation of IL-27 with IFN- $\gamma$ or IL-17A was evaluated by Pearson product-moment correlation coefficient. 


\section{Results}

\subsection{IL-27 is expressed similarly in plasma of RA and OA patients and HV, but is significantly}

higher in RA synovial fluid than in OA synovial fluid

To investigate the possible contribution of IL-27 to the pathogenesis of RA, we measured the concentration of IL-27 in the synovial fluid from patients with RA or OA, and in plasma from HV or patients with RA or OA. The IL-27 level in synovial fluid of RA patients (mean 0.13 $\mathrm{ng} / \mathrm{ml}$; range $0.017-0.37 \mathrm{ng} / \mathrm{ml})$ was significantly higher $(P<0.0005)$ than that in OA patients (mean $0.003 \mathrm{ng} / \mathrm{ml}$; range $0-0.033 \mathrm{ng} / \mathrm{ml}$ ) (Fig. 1). However, the concentrations of plasma IL-27 in RA patients (mean $0.45 \mathrm{ng} / \mathrm{ml}$; range $0.17-0.86 \mathrm{ng} / \mathrm{ml}$ ), OA patients (mean $0.34 \mathrm{ng} / \mathrm{ml}$; range 0.017-0.83 ng/ml) and HV (mean $0.48 \mathrm{ng} / \mathrm{ml}$; range 0.09-1.0 ng/ml) were similar (Fig. 1). These results imply that the joint environment by nature contains little IL-27 compared with the peripheral circulation, and that immunological inflammation of synovial tissue may contribute to the production of IL-27 in joints.

\subsection{IL-27 in RA synovial fluid originates not from RA FLSs but from MNCs}

To investigate the source of IL-27 in the synovial fluid of RA patients, we investigated the production of IL-27 by RA FLSs. RA FLSs stimulated with proinflammatory cytokines such as TNF- $\alpha$, IL-1 $\beta$, IL-6 or IL-17A failed to produce detectable IL-27 (Fig. 2A). We then evaluated 
the production of IL-27 by MNCs to investigate other origins of IL-27. Stimulated MNCs from synovial fluid and peripheral blood produced IL-27 protein (Fig. 2B). Interestingly, the production of IL-27 by MNCs in RA synovial fluid was significantly lower than that by MNCs from peripheral blood from RA and OA patients (Fig. 2B), as observed in figure 1. These results indicate that a population of MNCs can produce IL-27.

\section{3. $\mathrm{CD} 4^{+}$cells produce IL-27 and infiltrate RA synovium}

To determine the IL-27-secreting population in MNCs, we conducted intracellular staining of MNCs followed by flow cytometry. We stained MNCs with anti-CD4, -CD8, -CD14, or -CD19, and intracellular anti-IL-27. Only CD14 ${ }^{+}$cells were IL-27 positive (Fig. 3A). Immunohistochemistry showed that IL-27-producing $\mathrm{CD} 14^{+}$cells were present in RA synovium but rarely in OA (Fig. 3B). These results indicate that IL-27 in RA synovial fluid originates from $\mathrm{CD}_{14}{ }^{+}$cells infiltrating synovial tissue and synovial fluid.

\subsection{IL-27R is expressed on RA FLSS and is ubiquitously distributed in RA synovium}

Next, we investigated the distribution of IL-27R on RA synovial cells using immunohistochemical staining. IL-27R is a heterodimer composed of WSX-1 (IL-27R $\alpha$ ) and gp130. Because gp130 is known to be expressed on RA synovial cells [24], we investigated the 
expression of WSX-1 on RA FLSs and RA synovium. WSX-1 was expressed on RA FLSs and was ubiquitously distributed in RA synovium (Fig. 4A-D). These results indicate that FLS and most cell populations of synovium are under the control of IL-27 and that IL-27 might have widespread influence on the pathogenesis of RA.

\subsection{IL-27 suppresses the production of IL-6 or CCL20 induced by stimulation of RA FLSs with} proinflammatory cytokines

To investigate the influence of IL-27 on RA FLSs, we measured the production of proinflammatory cytokines by RA FLSs in the presence or absence of IL-27. Because the concentration of IL-27 in plasma or synovial fluid in RA was at most $1 \mathrm{ng} / \mathrm{ml}$ (Fig. 1), we used IL-27 at a maximum concentration of $10 \mathrm{ng} / \mathrm{ml}$. IL-27 alone failed to induce TNF- $\alpha$, IL-1 $\beta$, or IL-6 (Fig. 5A). However, IL-27 significantly suppressed the IL-6 production induced by TNF- $\alpha$ or IL-17A from FLSs (Fig. 5B). IL-27 also significantly suppressed the CCL20 production induced by TNF- $\alpha$ (Fig. 5C). These results suggest that IL-27 plays anti-inflammatory roles in two ways: both directly via the suppression of IL-6 production and indirectly by regulating recruitment of CCR6 ${ }^{+}$cells including Th17 cells, via the suppression of CCL20 production. Furthermore, the addition of decoy WSX-1 to these experiments significantly abrogated the suppression of IL-6 production induced by TNF- $\alpha$ from FLSs (Fig. 5D). These results indicate 
that stimulation of IL-27R with IL-27 has a suppressive effect on the production of proinflammatory cytokines.

3.6. IL-27 has positive correlation with IFN- $\gamma$ but weak negative correlation with IL-17A in the synovial fluid of RA.

IL-27 is known to induce Th1 development and suppress Th17 development $[9,12-15]$ and reduced the production of CCL20 (Fig. 5C). To evaluate the possible regulation in the development and the migration of Th cells by IL-27 in inflamed joints of RA, we measured the concentration of IFN- $\gamma$ and IL-17A in the synovial fluid of RA analyzed in figure 1 . The concentrations of IFN- $\gamma$ and IL-17A were $0.026 \mathrm{ng} / \mathrm{ml}$ on the average ranging from $0.004 \mathrm{ng} / \mathrm{ml}$ to $0.057 \mathrm{ng} / \mathrm{ml}$, and $0.052 \mathrm{ng} / \mathrm{ml}$ ranging from $0 \mathrm{ng} / \mathrm{ml}$ to $0.21 \mathrm{ng} / \mathrm{ml}$, respectively. The IL-27 level had significant positive correlation with the IFN- $\gamma$ level $(\mathrm{r}=0.56, \mathrm{p}=0.03)$, but weak negative correlation with the IL-17A level $(r=-0.30, p=0.27)$ (Fig. 6). These results indicate that IL-27 in the inflamed joints of RA has effect in the increase of IFN- $\gamma$ producing cells and reduction of IL-17A producing cells, implying induction of Th1 differentiation and suppression in the differentiation or the migration of Th17 cells by IL-27. 


\section{Discussion}

In this study, we showed that the concentration of IL-27 in plasma of RA and OA patients and $\mathrm{HV}$ was at most $1 \mathrm{ng} / \mathrm{ml}$, while that in synovial fluid of RA and OA was at most $400 \mathrm{pg} / \mathrm{ml}$ and $40 \mathrm{pg} / \mathrm{ml}$, respectively (Fig. 1). Recently, IL-27 at 10-100 ng/ml was reported to activate RA FLSs as an inflammatory cytokine [23]. In our laboratory, a high concentration (100 ng/ml) of IL-27 tended to induce IL-6 production from RA FLSs. However, based on the detected concentration of IL-27 in plasma or synovial fluid, we considered that a concentration of less than $10 \mathrm{ng} / \mathrm{ml}$ better reflects physiological conditions than a concentration of $10-100 \mathrm{ng} / \mathrm{ml}$.

Experimental autoimmune animal models or in vitro human studies suggest that Th17 cells play a crucial role in RA [1-4]. Indeed, clinical treatment for RA targeting IL-17A has shown significant effects [25]. Th17 cells specifically express the chemokine receptor CCR6, and its ligand CCL20 recruits Th17 cells into sites of inflammation [1, 5]. IL-27 has been reported to suppress the development of Th17 cells and the production of cytokines including IL-17A from $\mathrm{CD}^{+} \mathrm{T}$ cells by blocking RORC expression in humans and in several experimental animal models, whereas it induces Th1 differentiation [9, 12-15]. In our experiment of RA synovial fluid, the IL-27 level had significant correlation with the IFN- $\gamma$ level but weak negative correlation with the IL-17A level (Fig. 6). Although IFN- $\gamma$ and IL-17A can be produced by other cells than Th cells, these results implies that IL-27 in the inflamed joints of RA also induced Th1 
development and suppress the development or the migration of Th17 cells.

IL-27 also suppresses the production of CCL20 induced by TNF- $\alpha$ from human keratinocytes [10]. In our experiment with FLSs, IL-27 suppressed the production of CCL20 induced by TNF- $\alpha$ and the production of IL- 6 induced by TNF- $\alpha$ or IL-17A. These data collectively indicate that in RA, IL-27 suppresses not only the proinflammatory cytokine network but also the recruitment of $\mathrm{CCR}^{+}$cells including Th17 cells.

IL-27R is a heterodimeric receptor consisting of WSX-1 and gp130. gp130 is known to be expressed on RA synovial cells and although IL-27 binds to WSX-1, signal transduction in response to IL-27 is never seen without the combination of both components [7, 17, 24]. Therefore, the addition of decoy WSX-1 successfully neutralized the suppressive effect of IL-27 in our experiments (Fig. 5D). WSX-1 is expressed on FLSs, and is also ubiquitously distributed on RA synovium (Fig. 4A, C). These results indicate that IL-27 might have a widespread suppressive effect on the synovium in RA.

We have shown that CD14 ${ }^{+}$cells infiltrate RA synovium produce IL-27 (Fig. 3B). DCs as well as monocytes/macrophages might be included among these $\mathrm{CD} 14^{+} \mathrm{IL}-27^{+}$cells, because human circulating $\mathrm{CD} 14^{+}$monocytes have the capacity to differentiate into macrophages or DCs after immigration into extravascular tissues [26]. In particular, it was reported that human monocyte-derived DCs transdifferentiate into osteoclasts in the RA microenvironment, and that 
in the intermediate stage of the transdifferentiation they express CD14 and function as APCs [27].

From these results, we suggest that IL-27-producing $\mathrm{CD} 14^{+}$cells might be circulating in peripheral vessels irrespective of RA or OA, but that these cells rarely migrate to normal synovium or synovial fluid. This may be why the concentration of IL-27 in joints was lower. IL-27-producing $\mathrm{CD} 14^{+}$cells might preferentially infiltrate the synovium in RA joints and contribute to modification of joint inflammation. Notably, the sequence of anti-inflammatory mechanisms of IL-27 produced by CD14 ${ }^{+} \mathrm{IL}-27^{+}$cells infiltrating into RA synovium is one of the negative feedback systems acting against synovial inflammation in RA. Because IL-27 also suppresses the development of Th17 cells [9, 12-15], IL-27 is considered to protect joints from inflammation induced by Th17 cells. However, the IL-27 level in RA synovial fluid was lower than in RA peripheral blood (Fig. 1). This lower IL-27 level in RA joints might result in incomplete regulation of Th17 cells in RA joints and contribute to the severity and perpetuation of joint inflammation. This may be partly because the poor regional blood flow in joints causes less accumulation of $\mathrm{CD} 14^{+} \mathrm{IL}-27^{+}$cells compared with the peripheral circulation. Alternatively, the cytokine environment of the joint might affect the production of $\mathrm{IL}-27$ by CD14 ${ }^{+}$cells. In this respect, reinforcement of the suppressive function of IL-27 might be a novel therapeutic agent targeting RA, although the role of IL-27 in human immunity is so complex that further research 
is required.

In conclusion, $\mathrm{CD} 14^{+} \mathrm{IL}-27^{+}$cells specifically infiltrate the synovium after the onset of RA, and IL-27 plays anti-inflammatory roles in RA. IL-27 inhibited not only the production of IL-6 from RA FLSs but also the recruitment of $\mathrm{CCR}^{+}$cells including Th17 cells into RA joints by suppressing the production of CCL20 from RA FLS. This sequence is regarded as one of the negative feedback systems against inflammation in RA. 


\section{Acknowledgments}

This study was supported by health and Labor Science Research Grants for Research on Allergic Disease and Immunology from the Ministry of Health, Labor and Welfare (Grant No. 10103190). We thank J. Toguchida, T .Aoyama, and K. Yamamoto for technical support. 


\section{Figure legends}

\section{Fig. 1. The concentration of IL-27 in plasma or synovial fluid of RA or OA patients.}

The concentrations of IL-27 in plasma of RA (RAPB) patients, OA (OAPB) patients and healthy volunteers (HVPB) ( $\mathrm{n}=15$ per group) or synovial fluid of RA (RASF) and OA (OASF) patients were measured by ELISA. Vertical bars represent the means \pm SD. Significant differences between RASF and RAPB are indicated by $* * * P<0.0005$.

\section{Fig. 2. MNCs but not FLSs produce IL-27.}

(A) RA FLSs were incubated for $48 \mathrm{~h}$ with vehicle or the indicated cytokine at a concentration of 2 or $10 \mathrm{ng} / \mathrm{ml}$ and the concentration of IL-27 in the triplicate supernatants was measured by ELISA. Recombinant IL-6 was added together with 100 ng/ml sIL-6R, because FLSs express little membranous IL-6R. (B) The concentrations of IL-27 in the culture supernatants of MNCs from peripheral blood of RA (RAPB, $n=26)$ and OA $(O A P B, n=17)$ patients and synovial fluid of RA (RASF, $n=16$ ) patients were measured by ELISA. Vertical bars represent the means \pm SD.

Significant differences are indicated by $* * P<0.005$. N.S. not significant. N.D. not detectable.

Fig. 3. CD14 ${ }^{+}$cells in MNCs and synovium produce IL-27. 
(A) Following PMA/ionomycin and GolgiStop stimulation, MNCs of healthy volunteers were stained with antibodies to the indicated surface antigens and IL-27 and analyzed by flow cytometry. The results represent three independent experiments. (B) RA or OA synovial synovium was stained with anti-CD14 (red) and IL-27 (green) antibodies and observed by confocal microscopy. In these images, $\mathrm{CD} 14^{+} \mathrm{IL}-27^{+}$cells are depicted as yellow. The upper left or right panel is the image of RA synovium with anti-CD14 or anti-IL-27 antibodies, respectively. The lower left or right panel is the image of RA synovium or OA synovium, stained with anti-CD14 and anti-IL-27 antibodies, respectively. Representative staining of each group is shown.

Fig. 4. WSX-1 is ubiquitously expressed on RA FLSs or synovium.

The expression of WSX-1 was analyzed by immunohistochemical staining of RA FLSs (A, B) and RA synovium (C, D). The left panels (A, C) show WSX-1 staining, and the right panels (B, D) show staining with isotype-matched control IgG. Representative staining of each group is shown.

Fig. 5. IL-27 suppresses the production of IL-6 and CCL20 from RA FLSs via WSX-1.

(A) FLSs of RA were incubated for $48 \mathrm{~h}$ with IL-27 at the indicated concentration and the 
concentrations of TNF- $\alpha$, IL- $1 \beta$ or IL- 6 in the triplicate supernatants were measured by

ELISA. (B) FLSs of RA were incubated for $48 \mathrm{~h}$ with $2 \mathrm{ng} / \mathrm{ml} \mathrm{TNF-} \alpha$ or IL-17A in

combination with IL-27 at the indicated concentration, and the IL-6 level in the triplicate supernatants was measured by ELISA. (C) FLSs of RA were incubated for $48 \mathrm{~h}$ with 10 $\mathrm{ng} / \mathrm{ml}$ TNF- $\alpha$ in combination with IL-27 at the indicated concentration, and the CCL20 level in the quadruplicate supernatants was measured by ELISA. (D) FLSs of RA were incubated for $48 \mathrm{~h}$ with $2 \mathrm{ng} / \mathrm{ml}$ TNF- $\alpha$ in the presence or absence of $2 \mathrm{ng} / \mathrm{ml} \mathrm{IL-27}$ in combination with $10 \mu \mathrm{g} / \mathrm{ml} \mathrm{IgG} \mathrm{control} \mathrm{or} 10 \mu \mathrm{g} / \mathrm{ml} \mathrm{WSX-1} \mathrm{Fc} \mathrm{chimera} \mathrm{and} \mathrm{the} \mathrm{IL-6} \mathrm{level} \mathrm{in} \mathrm{the}$ quadruplicate supernatants was measured by ELISA. Vertical bars represent the means \pm SD. Significant differences compared with samples without the addition of IL-27 are indicated by $* P<0.05$. N.D. not detectable.

Fig. 6. The correlation of IL-27 with IFN- $\gamma$ or IL-17A in the synovial fluid of RA.

The concentrations of IFN- $\gamma$ or IL-17A in the synovial fluid of RA patients analyzed in figure 1 were measured by ELISA $(n=15)$. Pearson product-moment correlations of the IL-27 level with the IFN- $\gamma$ level or the IL-17A level are shown. Correlation coefficients (r) and p values are shown. 


\section{References}

[1] Hirota K, Yoshitomi H, Hashimoto M, Maeda S, Teradaira S, Sugimoto N, et al. Preferential recruitment of CCR6-expressing Th17 cells to inflamed joints via CCL20 in rheumatoid arthritis and its animal model. J Exp Med. 2007;204:2803-12.

[2] Nakae S, Saijo S, Horai R, Sudo K, Mori S, Iwakura Y. IL-17 production from activated T cells is required for the spontaneous development of destructive arthritis in mice deficient in IL-1 receptor antagonist. Proc Natl Acad Sci U S A. 2003;100:5986-90.

[3] Park H, Li Z, Yang XO, Chang SH, Nurieva R, Wang YH, et al. A distinct lineage of CD4 T cells regulates tissue inflammation by producing interleukin 17. Nat Immunol. 2005;6:1133-41.

[4] Yago T, Nanke Y, Ichikawa N, Kobashigawa T, Mogi M, Kamatani N, et al. IL-17 induces osteoclastogenesis from human monocytes alone in the absence of osteoblasts, which is potently inhibited by anti-TNF-alpha antibody: a novel mechanism of osteoclastogenesis by IL-17. J Cell Biochem. 2009;108:947-55.

[5] Tanida S, Yoshitomi H, Nishitani K, Ishikawa M, Kitaori T, Ito H, et al. CCL20 produced in the cytokine network of rheumatoid arthritis recruits CCR6+ mononuclear cells and enhances the production of IL-6. Cytokine. 2009;47:112-8.

[6] Kochi Y, Okada Y, Suzuki A, Ikari K, Terao C, Takahashi A, et al. A regulatory variant in CCR6 is associated with rheumatoid arthritis susceptibility. Nat Genet. 2010;42:515-9.

[7] Pflanz S, Timans JC, Cheung J, Rosales R, Kanzler H, Gilbert J, et al. IL-27, a heterodimeric cytokine composed of EBI3 and p28 protein, induces proliferation of naive CD4(+) T cells. Immunity. 2002;16:779-90.

[8] Stumhofer JS, Hunter CA. Advances in understanding the anti-inflammatory properties of IL-27. Immunol Lett. 2008;117:123-30.

[9] Niedbala W, Cai B, Wei X, Patakas A, Leung BP, McInnes IB, et al. Interleukin 27 attenuates collagen-induced arthritis. Ann Rheum Dis. 2008;67:1474-9.

[10] Shibata S, Tada Y, Kanda N, Nashiro K, Kamata M, Karakawa M, et al. Possible roles of IL-27 in the pathogenesis of psoriasis. J Invest Dermatol.2010;130:1034-9.

[11] Larousserie F, Pflanz S, Coulomb-L'Hermine A, Brousse N, Kastelein R, Devergne O. Expression of IL-27 in human Th1-associated granulomatous diseases. J Pathol. 2004;202:164-71.

[12] Batten M, Li J, Yi S, Kljavin NM, Danilenko DM, Lucas S, et al. Interleukin 27 limits autoimmune encephalomyelitis by suppressing the development of interleukin 17-producing $\mathrm{T}$ cells. Nat Immunol. 2006;7:929-36.

[13] Stumhofer JS, Laurence A, Wilson EH, Huang E, Tato CM, Johnson LM, et al. Interleukin 27 negatively regulates the development of interleukin 17-producing $\mathrm{T}$ helper cells during chronic inflammation of the central nervous system. Nat Immunol. 2006;7:937-45. 
[14] Diveu C, McGeachy MJ, Boniface K, Stumhofer JS, Sathe M, Joyce-Shaikh B, et al. IL-27 blocks RORC expression to inhibit lineage commitment of Th17 cells. J Immunol. 2009;182:5748-56.

[15] Murugaiyan G, Mittal A, Lopez-Diego R, Maier LM, Anderson DE, Weiner HL. IL-27 is a key regulator of IL-10 and IL-17 production by human CD4+ T cells. J Immunol. 2009;183:2435-43.

[16] Sprecher CA, Grant FJ, Baumgartner JW, Presnell SR, Schrader SK, Yamagiwa T, et al. Cloning and characterization of a novel class I cytokine receptor. Biochem Biophys Res Commun. 1998;246:82-90.

[17] Pflanz S, Hibbert L, Mattson J, Rosales R, Vaisberg E, Bazan JF, et al. WSX-1 and glycoprotein 130 constitute a signal-transducing receptor for IL-27. J Immunol. 2004;172:2225-31.

[18] Yoshida H, Miyazaki Y. Regulation of immune responses by interleukin-27. Immunol Rev. 2008;226:234-47.

[19] Kalliolias GD, Zhao B, Triantafyllopoulou A, Park-Min KH, Ivashkiv LB. Interleukin-27 inhibits human osteoclastogenesis by abrogating RANKL-mediated induction of nuclear factor of activated T cells $\mathrm{c} 1$ and suppressing proximal RANK signaling.2010 Arthritis Rheum.62:402-13.

[20] Furukawa M, Takaishi H, Takito J, Yoda M, Sakai S, Hikata T, et al. IL-27 abrogates receptor activator of NF-kappa B ligand-mediated osteoclastogenesis of human granulocyte-macrophage colony-forming unit cells through STAT1-dependent inhibition of c-Fos. J Immunol. 2009;183:2397-406.

[21] Cao Y, Doodes PD, Glant TT, Finnegan A. IL-27 induces a Th1 immune response and susceptibility to experimental arthritis. J Immunol. 2008;180:922-30.

[22] Goldberg R, Zohar Y, Wildbaum G, Geron Y, Maor G, Karin N. Suppression of ongoing experimental autoimmune encephalomyelitis by neutralizing the function of the p28 subunit of IL-27. J Immunol. 2004;173:6465-71.

[23] Wong CK, Chen da P, Tam LS, Li EK, Yin YB, Lam CW. Effects of inflammatory cytokine IL-27 on the activation of fibroblast-like synoviocytes in rheumatoid arthritis. Arthritis Res Ther. 2010; 12:R129.

[24] Rose-John S, Scheller J, Elson G, Jones SA. Interleukin-6 biology is coordinated by membrane-bound and soluble receptors: role in inflammation and cancer. J Leukoc Biol. 2006;80:227-36.

[25] Genovese MC, Van den Bosch F, Roberson SA, Bojin S, Biagini IM, Ryan P, et al. LY2439821, a humanized anti-interleukin-17 monoclonal antibody, in the treatment of patients with rheumatoid arthritis: a phase I randomized, double-blind, placebo-controlled, proof-of-concept study. Arthritis Rheum.62:929-39.

[26] Seta N, Kuwana M. Human circulating monocytes as multipotential progenitors. Keio J Med. 2007:56:41-7.

[27] Rivollier A, Mazzorana M, Tebib J, Piperno M, Aitsiselmi T, Rabourdin-Combe C, et al. Immature 
dendritic cell transdifferentiation into osteoclasts: a novel pathway sustained by the rheumatoid arthritis microenvironment. Blood. 2004;104:4029-37. 


\section{Table 1: Clinical features of the participants}

Characteristics

Number of participants

Sex, male/female

Age, mean (range)

Duration of RA (year), mean (range)

ESR (mm/hr), mean (range)

CRP (mg/dl), mean (range)

MMP3 (ng/ml), mean (range)

DAS28, mean (range)

Kellgren/Lawrence grade, $\mathbf{n}$

Medication, $\mathbf{n}$ (\%)

Predonisolone

Methotrexate

Infliximab

Eternercept

Tocilizumab

Tacrolimus

Salazosulfapyridine

Bucillamine

Gold
RA

28

$7 / 21$

59.2 (22 to 80 )

11.8 (0.5 to 46$)$

48.1 (4 to 119)

2.69 (0.0 to 9.6$)$

320 (87.1 to 800$)$

4.43 (2.23 to 7.13 )

NA

$20(71 \%)$

$18(67 \%)$

$2(7.1 \%)$

$2(7.1 \%)$

$2(7.1 \%)$

$4(14 \%)$

$6(21 \%)$

$3(11 \%)$

$1(3.5 \%)$
OA

HV

15

$7 / 8$

43.9 (32 to 58$)$

NA

NA

NA

NA

NA

NA

I :0, II :4, III :12,IV :10

NA

NA

NA

NA

NA

NA

NA

NA

NA

NA

RA: rheumatoid arthritis, OA: osteoarthritis, HV: healthy volunteers, ESR: erythrocyte sedimentation rate, CRP: Creactive protein, MMP-3: metalloproteinase-3, DAS28: 28-joint Disease Activity Score, NA: not applicable 


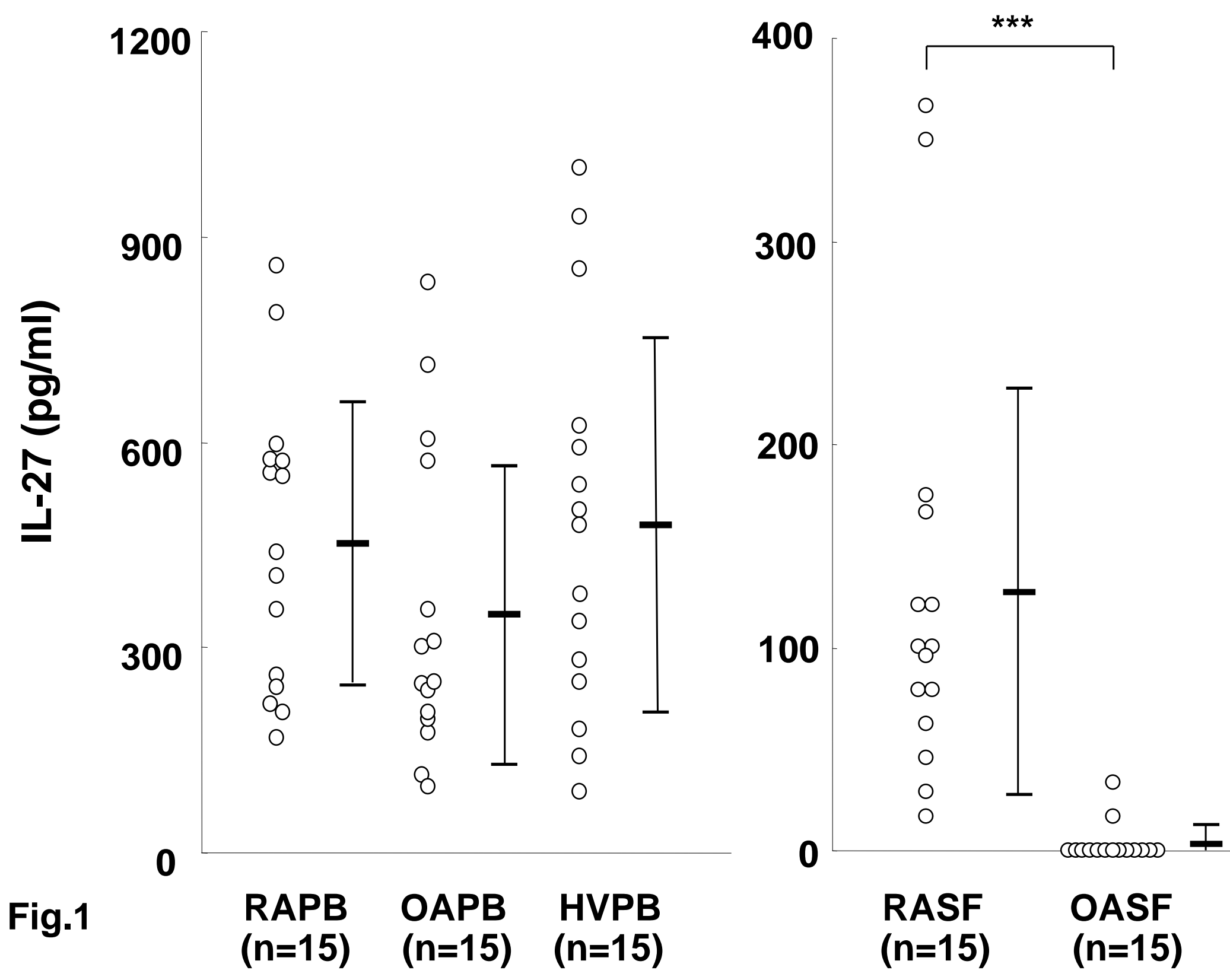



A.

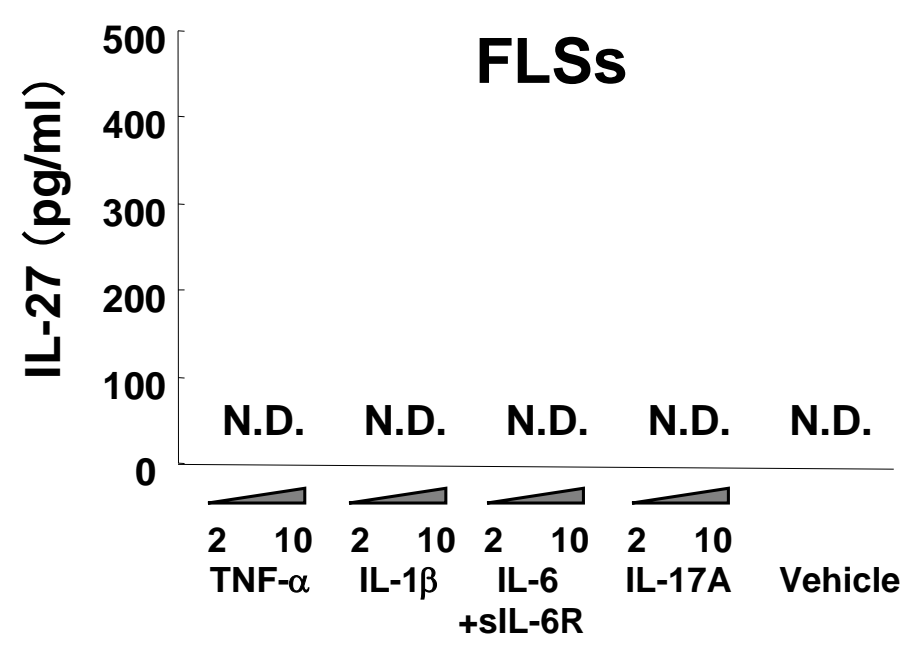

B.

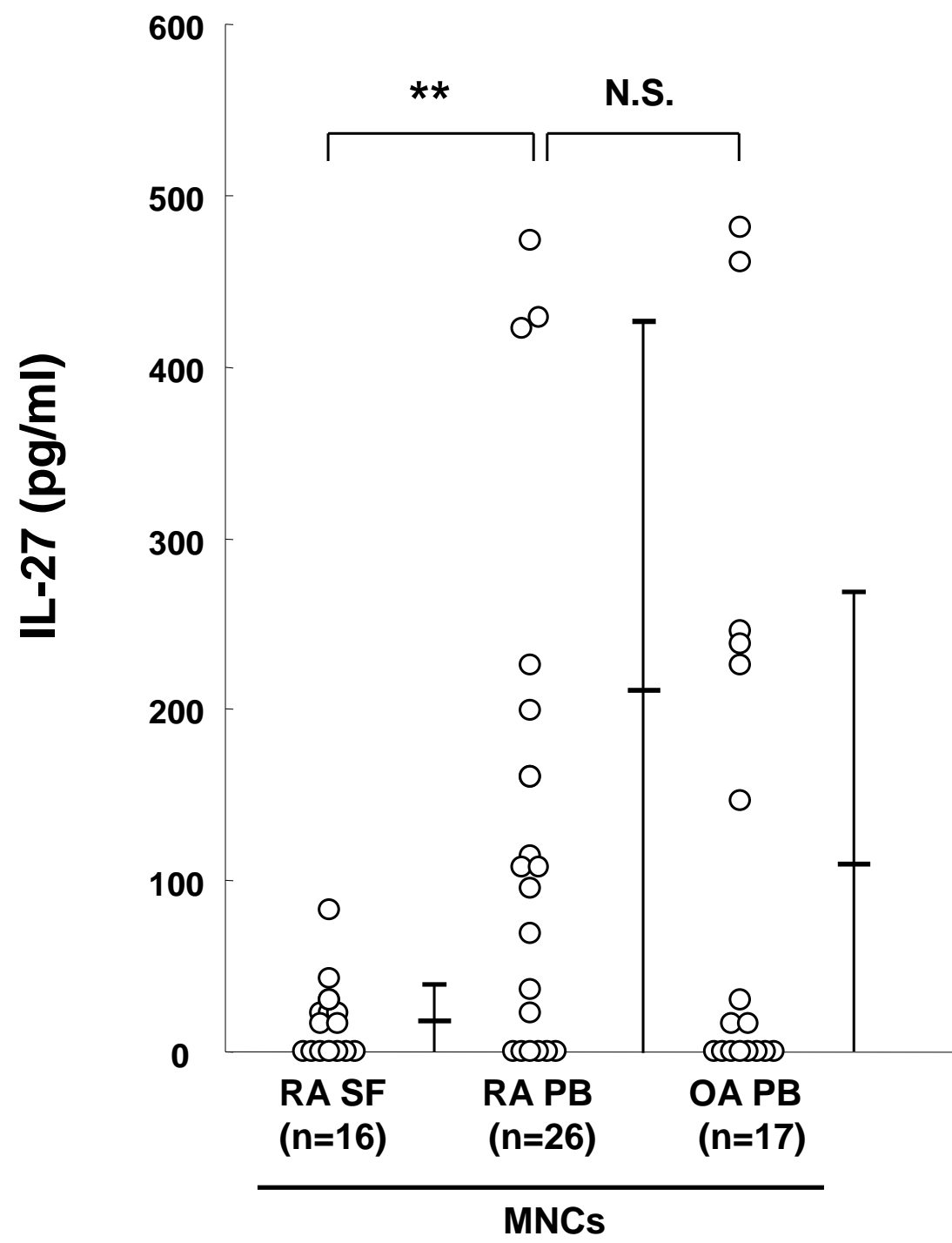




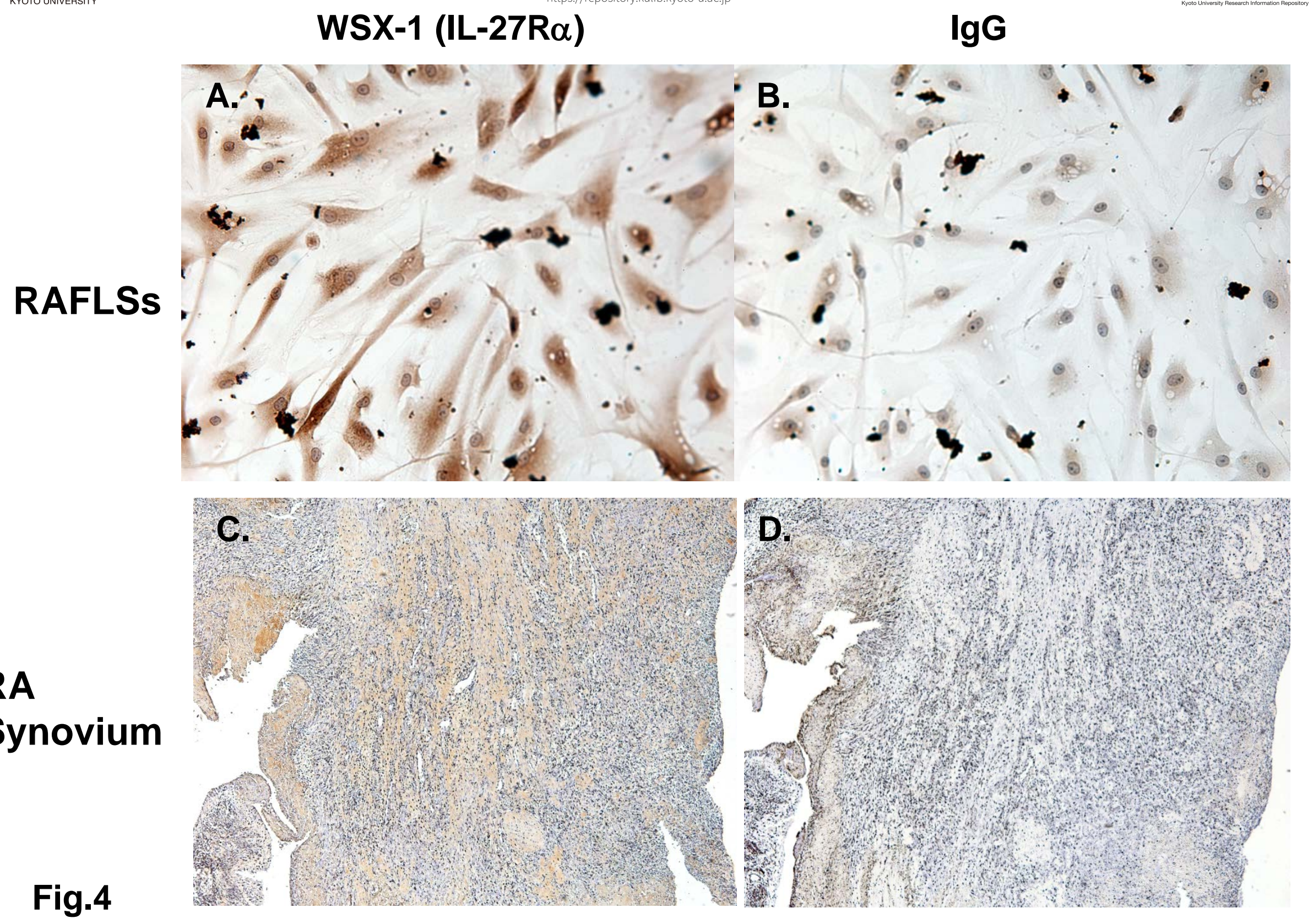

\section{RA \\ Synovium}

Fig.4 
ㄱ. 京都大学

KYoTo u

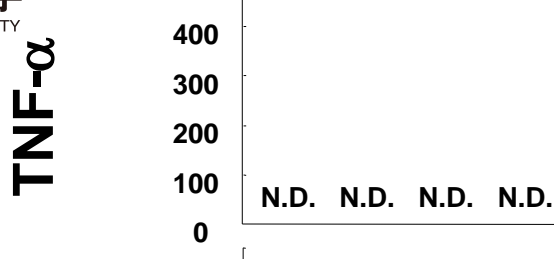

C.
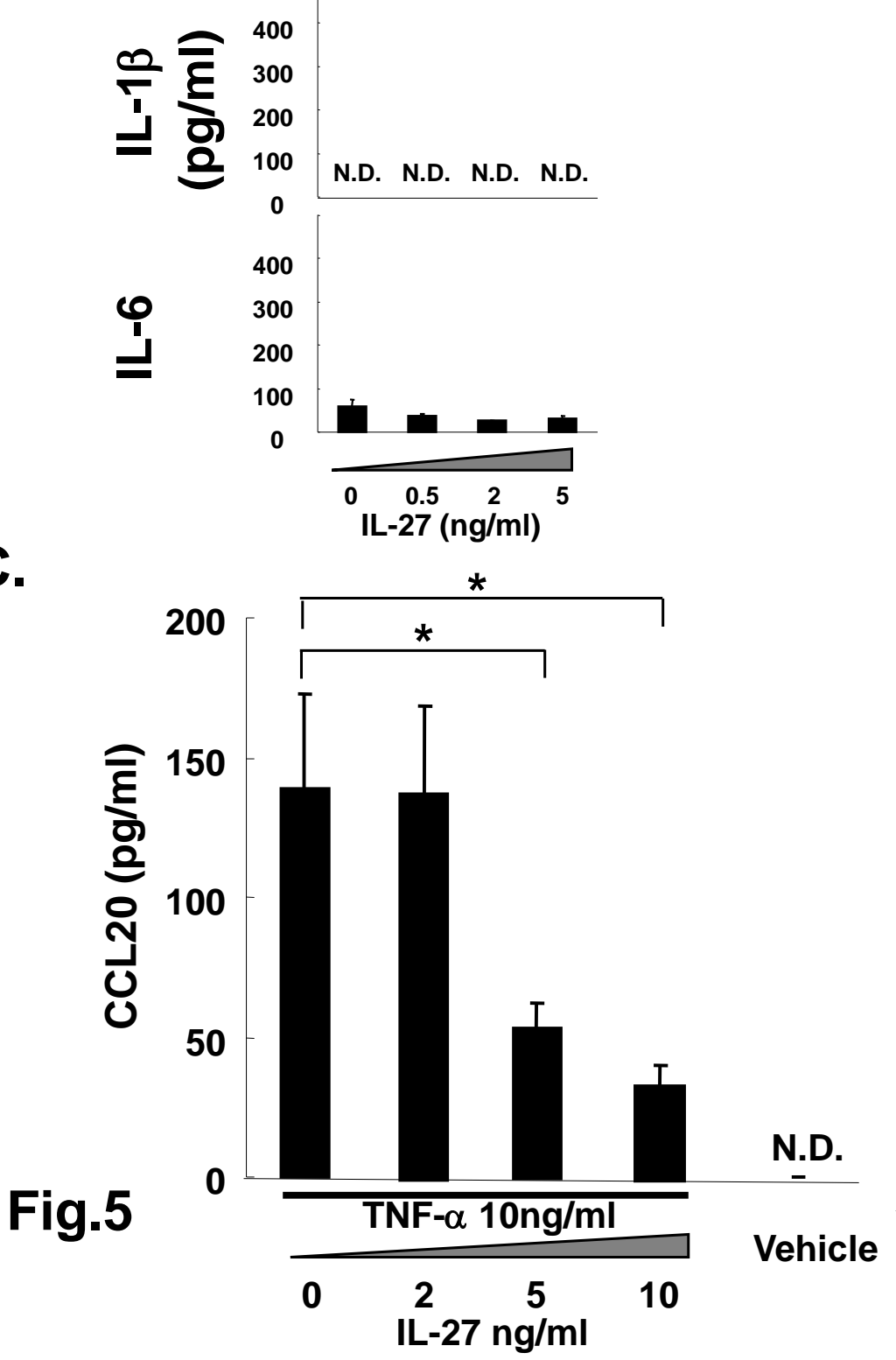

Q

*

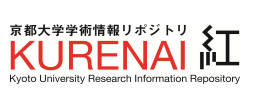

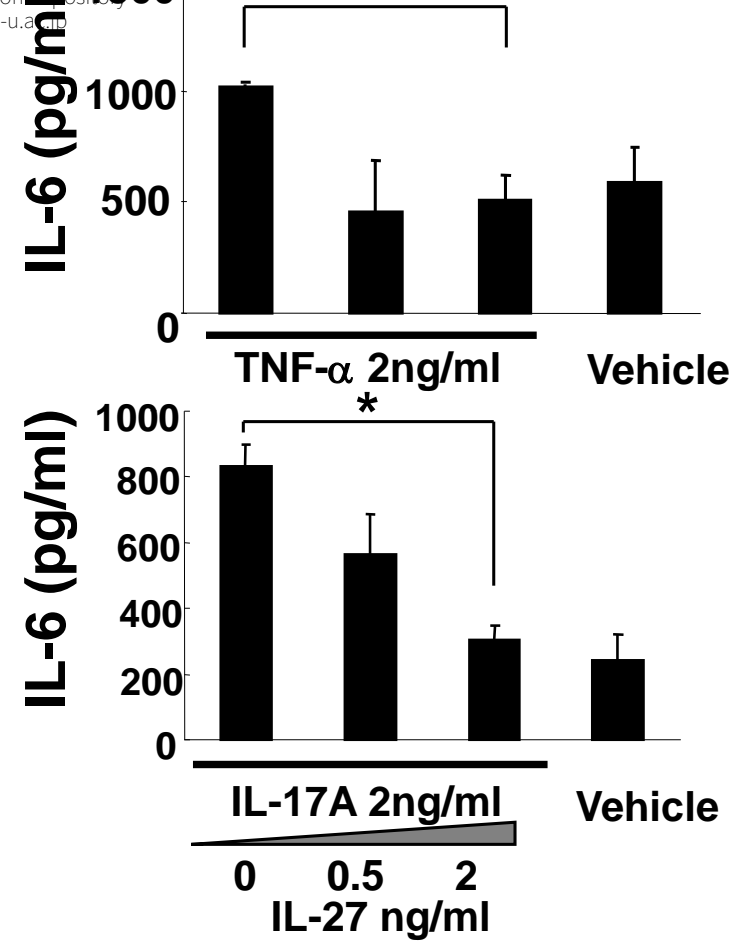

D.

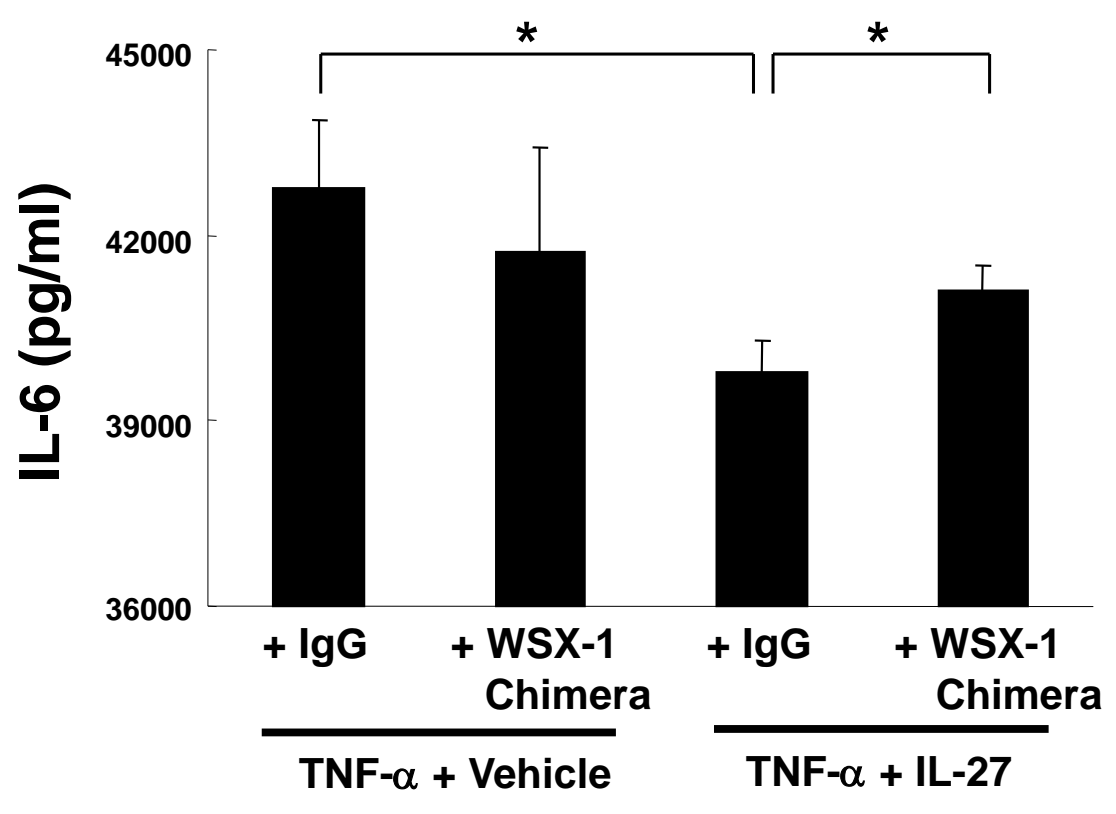




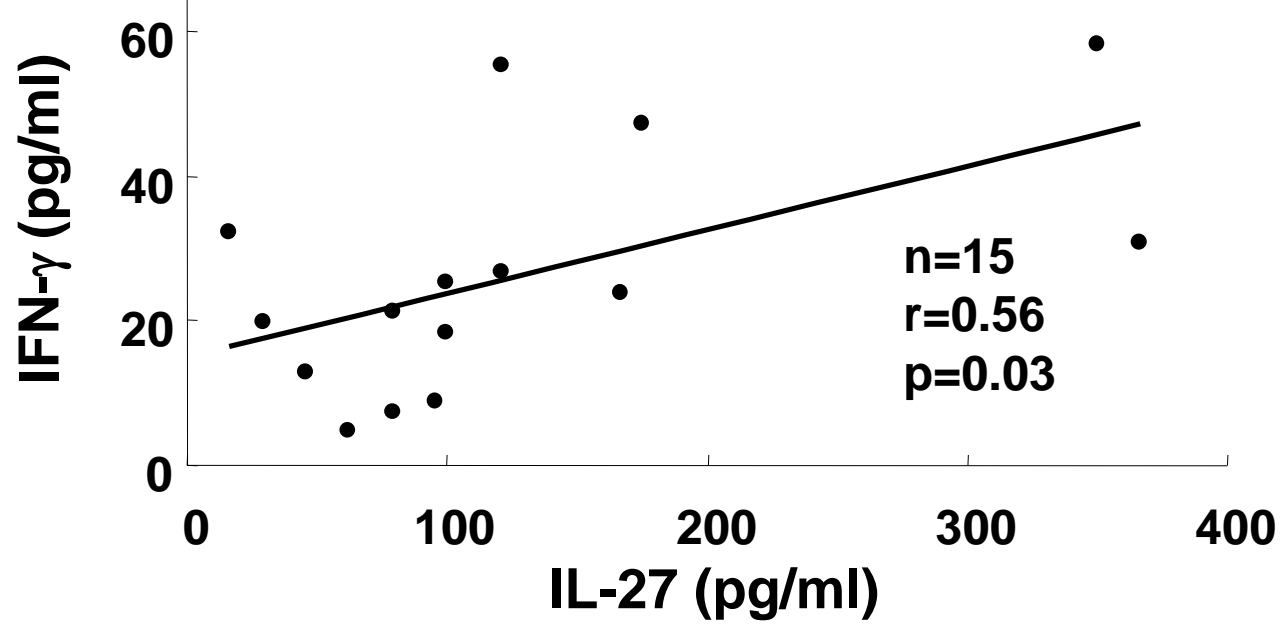

250

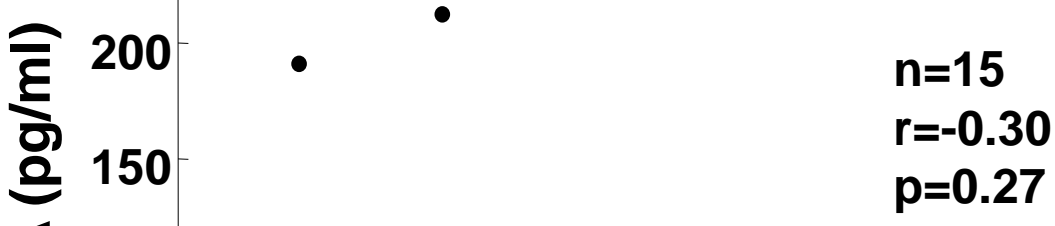

Fig. 6

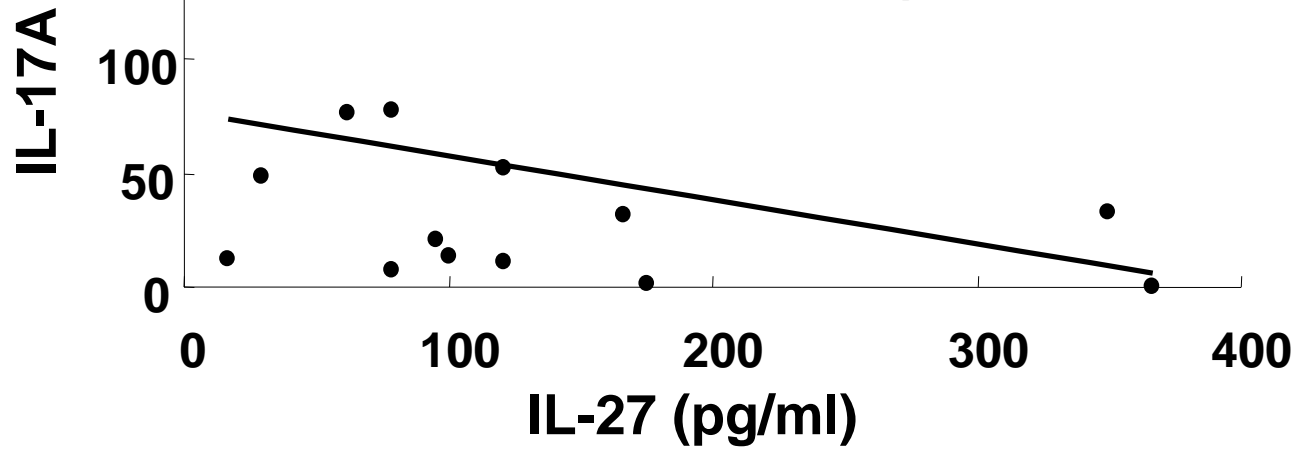

